\title{
Path Creation: a Comparative Study of new Product Development Perspective
}

\author{
Yin liping \\ College of Business Administration, Capital University of Economics and Business, \\ 10070 , Beijing, China \\ yinliping6@hotmail.com
}

Keywords: path creation, comparison, radical innovation

\begin{abstract}
Existing literature does not explain well why incumbent high-tech enterprise can not engaged in breakthrough innovation for path creation in the tide of mobile Internet revolution. This article through deeply comparative analysis the new product development process of the two PC companies, finds the three reasons that the incumbent can not engage in groundbreaking innovation. This article makes up lack of the existing innovation theory, especially from the incumbent firm of a developing country perspective.
\end{abstract}

\section{Introduction}

The existing innovation literatures have been extensive and in-depth discussion of the incumbent firms that can not engage in breakthrough innovation to reshape their development path[1].Still there are a lot of such cases after the rise of Internet innovation. Nokia is the king of the function phone market. Many years ago before the rise of the smart phone market, Nokia has developed a smart phone in the lab, then quickly put it into the market. But Smart phone market has not been opened because of lack of the user awareness. Although the standstill of the smart phone business development, function phone business was booming only through the simple industrial design. Nokia eventually returned its resources to the function phone market, gave up pioneering smart phone market. Existing innovation theory explains the failure of incumbent corporations. One of those reasons is that it fail to identify new opportunities for breakthrough innovation. Incumbent firms easily regard a breakthrough innovation as a threat rather than an opportunity. But we found that the interpretation is not suitable for Nokia in this case. Developing smart phone showed the company had realized the future trend of the mobile phone market. Dominant logic is another explanation theory that incumbent firms fail to conduct in radical innovation. Dominant logic is a mode of thinking which is formed during a successful product development process in the past. The dominant logic explains why Kodak can not successfully transition from the film business to the digital business. Kodak first invented a digital camera, but it followed the old film business model in the development of digital business. However, the dominant logic is not a good account for the failure of Nokia in the smart phone market. In Nokia's case, we do not see impact of the old mode of thinking on new business development. Similar to Nokia, Lenovo is also Chinese one that realized smart phones opportunities very early. But, the real winner of the smart phone market is Apple. Existing innovation theories can not explain their failure well. The purpose of this paper is to probe why the former two companies did not dominate the smart phone market from new product development perspective.

\section{Apple's smart phone development}

In 1996, Jobs returned to Apple almost on the verge of bankruptcy. The first thing he did was cut off the handheld Newton and printers, and substantially reduced its PC product line. Based on the analysis of the trend of development of Internet, Apple decided to develop digital player ipod, capable of storing 1,000 songs. This product was seek after by consumers due to simple design, easy to use. This product was a great success. In order to avoid the market erosion of smart phone embedded music player, Apple started the research and development of its smart phone . Apple and Motorola launched the first smart phone called“ ipod on the phone "in 2005[2]. This machine was 
very unsuccessful. It could not directly download songs from Internet, only stored 100 songs. Later, Apple decided to bring out its smart phones alone. In 1997, Apple developed the first smart phone called iphone. Different from the physical keyboard of the Black Berry, Apple adopt multi-touch technology, used a virtual keyboard in iphone1. Virtual Keyboard revolutionarily redefined the smart phone, which greatly improves the user experience especially in a mobile internet environment. In addition to multi-point technology, distinctive, highly humane industrial design of the Apple smart phone is also its magic weapon of huge market success. Apple's product development process has very unique features. In general product development process, development and manufacturing of the product's features works in the first place, industrial design in the post place. But in Apple, this is the opposite order. The development and manufacturing engineers of iphone must follow the new product requirements proposed by industrial designers. People in other departments should submit to the designer's ideas. In addition, Apple used ARM11 chips of a cheap low-energy, fast enough in iphone. Compared to past, the chip greatly expanded the smart phone's features. Last, iphone success thanks to Apple's unique ability to integrate production system closely. Different from traditional PC, Apple's product system is relatively closed one, which allows Apple to integrate hardware, operating system with application software, providing end-end quality product to consumers. But noly product innovation is not far enough to success. M.A.schilling (2005)[3] put forward that a product create value for consumers in three ways . Functions provided by a product itself, user scale, Ancillary products. Iphone have been able to create value for consumers in the three ways. first, because it is a collection of a large number of functions, the traditional phone, music player, video player, game consoles, PC, etc. Second, these basic functions are not enough for success. To play their role, there must be ancillary products. To this end, Apple has developed Apple's online store, selling a variety of ancillary products, including a large number of music priced by a dollar, games and application software. These ancillary products promote more people to use of basic products, in reverse more users scale prompt more ancillary products produced, which form a virtuous circle of customer value creation. Compared to the previous smart phone, iphone bring more new value to consumer at reasonable price.

\section{Lenovo's smart phone development}

In1997, Lenovo started smart phone business. Until 2003, the first smart phone ET180 based on Window mobile system was published. In 2004, Lenovo launched ET960 and got design honors award by the U.S. Association of IDEA. In the products development process, developers experienced many setbacks, even the most simple touch pen is the result of trial and error. Lenovo developed smart phones G900 and P102 with handwriting function based on the Lunix system after 2005. Star product Beacon08 shined in 2008 Beijing Olympic Games. These smart phones developed from scratch and also experienced the process from coarse to fine. Lenovo gained valuable experience in the development of the products. In 2010, with the maturing of the Andrew system, Lenovo assessing the situation, launched the first generation of lphone 3GW100 that combined new design and patented technology. As Lenovo's first Android smart phone, its biggest advantage is the price, almost half of Apple's smart phone price then. But the product had a lot of problems, not being compared with Apple's iphone. In 2011, Lenovo's lphone series cut in"thousand machine" market, the product types also increased to 19 models. The firm according to different market segments rapidly developed appropriate product models to meet the needs of consumers. At present there are already four series lphone, Including K-series owning prominent photography function, slim, stylish $\mathrm{S}$ series, business almighty $\mathrm{P}$ series, cost-effective $\mathrm{A}$ series with comprehensive coverage of the business, a long life, women, music, etc. To bring more consumers exceptional experience, Lenovo continued to refine classification of models and different positioning. lphone have more extensive product line, Lenovo developed 19 models smart phones in 2011, 33 models smart phones in 2012[4] . In machine sea tactics targeting Samsung, Lenovo lphone market share from less than 1\% jumped to 15.6\% from 2010 to 2012, ranking second in 
China's smart phone market, Temporarily ahead of Apple, and other front-line smart phone brands.

Although in quantity, Lenovo lphone has made temporary lead, but the future prospects is not optimistic. According to the China Internet consumer research center[5], in China's smart phone market products concerned rankings, there is not any Lenovo products on top 15. Belong to the Android system smart phones camp, Samsung smart phones obtained the highest degree of concern in the Chinese market in 2012. Samsung sold 87 models smart phones, far more than the Lenovo product models. It can be said that Samsung's extensive product line in the Chinese market make it meet the needs of various market segments. Samsung ranked the first in Chinese smart phone sales. In the high-end market, Lenovo can not compete with Apple, Samsung. In the mid-low-end market, in addition to competing with Samsung, Lenovo competes with a large number of Chinese domestic smart phone enterprises . According to data released by Shiner[6], as of the end of November 2012, China's share of total domestic smart phone has reached $71.7 \%$. However, $80 \%$ of this share is those priced in $1000 \sim 2000$ Yuan machines, they occupied most of the domestic smart phone market share. Regardless of 2012 Chinese smart phone market situation changes, Samsung and Apple dominate the smart phone market $99 \%$ of the profits. domestic smart phone manufacturers seize more than half of the market share, but the share of profits less than 1\%. Behind domestic smart phone in 2012 achieving unprecedented prosperity lurks an even greater crisis. The price war will be the primary means of business competition among the domestic smart phone firms.

\section{Discussion}

From smart phone industry innovation, we see that as PC background smart phone manufacturers, On way to path creation across two different industries, Apple and Lenovo achieved different results. Apple by entering the smart phone industry achieves great development and quickly grows into a world-class enterprise. Despite the fact of entering the mobile phone industry earlier than Apple, Lenovo did not get real success. From the innovation strategy perspective, we believe that Lenovo has its inevitable reason of failure. First, time to enter the smart phone industry for Lenovo is not appropriate. Before Apple entering smart phone, smart phone has been a high-end market segment for business people to use. RIM provided mobile office phone able to send and receive messages and dominated the small market. When Lenovo entered this market, newer and better product technology did not appear yet, Therefore, its failure is inevitable. In 2007, When Apple intended to enter the market, low-power chips technology decidinging Smart phone new features has matured, it is possible to achieve more PC functionality on a mobile phone at low price, thus Apple quickly used this chip technology and launched its own smart phone. Second, the Lenovo lacked the extraordinary ability to integrate new technologies owned by Apple. Complying with the development trend of future wireless internet, Apple by combining all kinds new technological, redefines the smart phone, and the successfully cut into the smart phone mass market. Without super ability to integrate, Apple is very difficult to compete over the existing smart phones enterprises. Third, the Lenovo lacked the ability to create new value for customers through lphone. Apple negotiated with major music manufacturers, to provide consumers with a large number of downloadable music. Iphone have numerous video, Application software for user.

\section{Conclusion}

When High-tech firms cross the chasm between old and new industries, just to get rid of the shackles of path dependence is not for enough, it is necessary that high-tech enterprises carry out a scientific path creation strategy. The first is the discovery or the creation of opportunity. Collecting and analyzing the evolution of new technologies are still very important for insighting into the opportunity of the emerging industry. As a developing country's high-tech enterprises, well away from sources of new technologies, even if they have a long-term expectations for the future development of the smart phone industry, it is difficult for Lenovo to seize the smart phones 
opportunities. But, this does not mean there is no chance for the enterprises like Lenovo. Samsung is a good example. After the study of major defects of Apple's smart phone, Samsung released its smart phone by rapid improvement Apple' product defects. There always are this or that defects in the leader' product, so latecomers have the opportunity to enter the market. Early imitation innovation strategy in emerging markets is still very valuable. Second, in the path creation, the ability to creat new resources and integrate all kinds of old resources are also very critical to seize new chance. Apple's ability to integrate is closely related to its vertical integration capability in the PC field. Lenovo innately lack of such resources combined capacity in the path creation. Lenovo only accumulated mass manufacturing capabilities in the PC, which not suitable for the innovative activities of path creation. Therefore, the firm must learn to new capabilities in order to engage in path create activities. The third, path creation is to create value for consumers. Apple's smart phone provide consumers with unparalleled product value. In the past, smart phones can only send and receive mail. Apple's smart phone is able to achieve more PC entertainment features, watching videos, listening to music, reading magazines and books, playing games in the wireless network environment, create a high consumer value. In the course of these entertainment consumers have from the passive consumption of traditional media in the past, transformed into active consumption today.

\section{Acknowledgements}

This paper has been funded by face projects (sm201210038009) of Beijing Municipal Education Commission.

\section{References}

[1] C. Christensen: innovator's dilemma. Jiangsu People's Publishing House (1997)

[2] http://tech.163.com/08/0115/14/428NGRBV000915BE.html

[3]M.A.schilling: Strategic Management of Technological Innovation (2nd Edition).Tsinghua University Press(2005),p54-p60

[4]Lenovo smart phone development history: http://www.ifanr.com/special/lenovo-mobile-history

[5]2012-2013 Chinese smart phone market research report: http://tech.hexun.com/2013-01-11/150040972.

[6] Lenovo smart phone second is short-lived?:http://it.sohu.com/20120726/n349034388.shtml 